\title{
RESENHA
}

\section{HISTORIA DE LAS UNIVERSIDADES LATINOAMERICANAS: TRADICIÓN Y MODERNIDAD}

\author{
History of Latin American universities: tradition and modernity
}

Celina Lertora Mendoza

Universidad del Salvador, Argentina.

\begin{abstract}
$\cos 80$
FLACHS, María Cristina Vera de (edit.). Historia de las universidades latinoamericanas: tradición y modernidad. Córdoba: Báez-Innovat/Conicet, 2013.
\end{abstract}

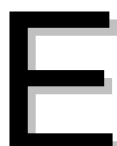

n 2013 se cumplieron cuatro siglos de la donación que hiciera el obispo Trejo y Sanabria a la Universidad de Córdoba, que comenzó su actividad docente manteniendo su continuidad sustancial a lo largo de todo este tiempo. Este hecho, así como el prestigio de la institución, indicaba la oportunidad de organizar una actividad académica de envergadura, y no sólo algún acto celebratorio olvidable. Por eso es altamente encomiable la tarea que ha tomado a su cargo la dra. Cristina Vera, especialista en historia universitaria y en especial cordobesa, de organizar una publicación que llenara el vacío mencionado.

Dos características señalan, además, la originalidad y el valor de esta tarea. Ambas son indicadas por la dra. Vera en la Presentación. Por una parte, presentar la historia cordobesa en el marco histórico de otras universidades hispano y luso americanas, convocando a especialistas de varios países. Por otra, se ha seguido el criterio de vincular la historia específicamente institucional a la realidad socio-política de cada época, buscando exhibir los vínculos entre universidad y sociedad. No todos los países están 
representados, pero como dice el proverbio lo perfecto es enemigo de lo bueno, y el conjunto de trabajos, que analiza la historia de las universidades más antiguas y prestigiosas, constituye un dossier muy importante ya que, como también se recuerda en la Presentación, desde los enjundiosos pero ya bastante antiguos de Águeda Rodríguez Cruz, y salvo la excepción de un número de la Revista de Historia de la Educación Latinoamericana (2006) carecemos de obras de conjunto sobre este importante tema.

Los trabajos se han agrupado por países, y éstos se presentan alfabéticamente. Por Argentina concurren dos trabajos. El de la propia dra. Vera: Tradición y modernidad en la historia de la Universidad de Córdoba, de mayor extensión que los demás, dado que es la universidad homenajeada, en el cual se traza su historia desde la fundación a la actualidad, siempre en relación a los sucesos políticos más resonantes. El segundo, La Universidad de Buenos Aires, sus pasos decimonónicos en búsqueda de un camino propio, de Celina A. Lértora Mendoza, analiza tres momentos: el fundacional, la época de la confederación y la institucionalización definitiva.

De Bolivia, los profesores Antonio Dubravcic Luksic y Bernardo Gantier Zelada escriben La Universidad Mayor, Real y Pontificia de San Francisco Xavier de Chuquisaca 1624-2013, un trabajo extenso y sólido que se centra en la época colonial, destacando la importancia de esta universidad en el movimiento independentista del Cono Sur, y luego abordan más extensamente los años de su modernización.

Maria Helena Cámara Bastos, de Brasil, en su aporte O ensino superior no Brasil: um percurso histórico, traza un panorama del desarrollo universitario brasileño que, si bien fue más tardío que en la zona hispana pues no tuvo universidades coloniales, ha tenido un crecimiento y una diversificación en la segunda mitad del siglo pasado, que coloca al país en un lugar privilegiado entre los de la región.

De Chile tenemos el aporte de Antonio Dougnac Rodríguez: Antecedentes, desarrollo y transformación de la Real Universidad de San Felipe de Santiago de Chile (1622-1843), refiriéndose a las dos primeras etapas de la universidad más importante del país.

Dos trabajos de conjunto se ocupan de Colombia. Maria Clara Guillen de Iriarte, sobre Las primeras universidades de Colombia, con oportunas puntualizaciones sobre las diferencias académicas de las instituciones educativas de nivel superior durante la colonia. Diana Soto Arango, en La universidad colombiana: políticas públicas y reformas educativas 1774-2012 traza el perfil de las propuestas de política universitaria desde el Plan de Moreno y Escandón hasta la actualidad, señalando interesantes continuidades en la problemática.

Tres trabajos se refieren a México. En primer lugar Enrique González González, especialista en historia de universidades coloniales, en La Real Universidad de México, de los orígenes a la consolidación ofrece una reconstrucción muy documentada sobre un período bastante confuso y discutido de la institución. Dando un salto temporal y ampliando el panorama, Renate Marsiske nos ofrece La Universidad de México en el siglo $X X$ : panorama general, donde un tema esencial, que es su especialidad, lo constituyen los movimientos estudiantiles y las reformas que suscitaron. Finalmente Armando Martínez Moya trabaja sobre otra universidad muy importante: Universidad de Guadalajara: dos momentos de su historia. Su largo recorrido fundacional colonial y su transición republicana. 
Elmer Robles Ortiz, de Perú, en Origen de las universidades más antiguas del Perú, donde concede, como es lógico, un lugar especial a la de San Marcos.

Finalmente, la investigadora española Remedios Ferrero Micó, que se ha dedicado con ahínco al estudio político-financiero comparado de las universidades hispánicas, cubre el área venezolana con su aporte Rupturas y pervivencias de la tradición jurídica y financiera de la universidad en Venezuela en la crisis del antiguo régimen.

Todos los trabajos finalizan con una selección bibliográfica y el detalle de los documentos utilizados, lo que permite a los lectores buscar más materiales de consulta y eventualmente continuar la investigación de alguno de estos interesantes temas.

CELINA ANA LÉRTORA MENDOZA es doctora en Filosofía por las Universidades Católica Argentina y Complutense de Madrid. Doctora en Teología por la Pontificia Universidad Comillas (España) y en Ciencias Jurídicas por la Universidad Católica Argentina. Actualmente es profesora en la Universidad del Salvador, donde dirige el postgrado especialización en Filosofía Argentina e Iberoamericana, y es profesora de doctorado, en el área Filosofía Argentina, en la Universidad Nacional del Sur.

Endereço: Fundación Fepai - Marcelo T. de Alvear 1640, 1 - E - 1060 - Buenos Aires - Argentina.

E-mail: fundacionfepai@yahoo.com.ar.

Recibido em 20 de maio de 2014.

Acepto em 17 de outubro de 2014. 